\title{
PENERAPAN MODEL CIRC UNTUK MENINGKATAN HASIL BELAJAR BAHASA INDONESIA TEMA PERISTIWA DALAM KEHIDUPAN PADA SISWA KELAS V SDN TAMBAKREJO TAHUN AJARAN 2019/2020
}

\author{
Solikhatun Diniah'1, Ngatman², Ratna Hidayah ${ }^{3}$ \\ Universitas Sebelas Maret \\ e-mail: solikhatundiniah97.uns@student.uns.ac.id
}

\section{Article History}

accepted 01/10/2020

approved 01/11/2020

published 01/12/2020

\begin{abstract}
Abstrak: Tujuan penelitian ini yaitu: (1) mendeskripsikan langkah-langkah penerapan model CIRC; (2) meningkatkan hasil belajar Bahasa Indonesia melalui penerapan model CIRC; (3) dan mendeskripsikan kendala dan solusi penerapan model CIRC dalam peningkatan hasil belajar Bahasa Indonesia. Penelitian tindakan kelas kolaboratif ini dilaksanakan dalam dua siklus. Subjek penelitian ini adalah guru dan siswa kelas V SDN Tambakrejo. Teknik pengumpulan data yang digunakan adalah observasi, wawancara, dan tes. Analisis data dilaksanakan melalui reduksi data, penyajian data, dan penarikan kesimpulan. Hasil penelitian menunjukkan bahwa: (1) langkah-langkah penggunaan model CIRC yaitu: a) orientasi, b) pembentukan kelompok, c) pembagian bacaan, d) diskusi, e) presentasi, f) kesimpulan, dan g) penutup; (2) penggunaan model CIRC dapat meningkatkan hasil belajar Bahasa Indonesia siswa terbukti dengan peningkatan rata-rata ketuntasan hasil belajar Bahasa Indonesia siswa pada siklus I yaitu 66,07\% dan siklus II yaitu $85,71 \%$; (3) kendala dalam penelitian ini yaitu: siswa kurang aktif bertanya, menjawab pertanyaan, dan berpendapat. Solusi untuk mengatasi kendala tersebut, yaitu guru membimbing, memotivasi, dan memberikan penghargaan kepada siswa yang berani berpendapat dan menjawab pertanyaan, sehingga siswa termotivasi untuk berani berpendapat di depan kelas. Simpulan dari penelitian ini adalah penggunaan model CIRC dapat meningkatkan hasil belajar Bahasa Indonesia pada siswa kelas V SDN Tambakrejo tahun ajaran 2019/2020.
\end{abstract}

Kata kunci : CIRC, Hasil Belajar, Bahasa Indonesia

\begin{abstract}
The study aimed: (1) to describe the steps in implementing the CIRC model, (2) to improve Indonesian language learning outcomes through the application of the CIRC model, and (3) to describe the obstacles and solutions in implementing the CIRC model in improving Indonesian language learning outcomes. It was collaborative classroom action research conducted in two cycles. The subjects were teacher and students of fifth grade of SDN Tambakrejo. Data collection techniques were observation, interviews, and tests. Data analysis were data reduction, data presentation, and drawing conclusion. The results showed that: (1) the steps to the application of Cooperative Integrated Reading and Composition (CIRC) model were: a) having orientation, b) forming group, c) distributing texts, d) having discussion, e) having presentation, f) drawing conclusions, and g) closing. (2) The application of CIRC model improved student Indonesian learning outcomes. The averages of student mastery in Indonesian language learning outcomes were $66.07 \%$ in cycle I and $85.71 \%$ in cycle II. (3) The obstacles were: the students were passive in asking questions, answering questions, and giving opinions. The solutions to overcome the obstacles were the teacher guided, motivated, and gave reward to students giving opinions and answering questions so that the students had courage to give opinions in front of the class. It concludes that the application of Cooperative Integrated Reading and Composition (CIRC) model improves Indonesian language learning outcomes to fifth grade students of SDN Tambakrejo in academic year of 2019/2020.
\end{abstract}

Keywords: CIRC, learning outcomes, Indonesian language 


\section{PENDAHULUAN}

Pendidikan berperan penting untuk meningkatkan kualitas sumber daya manusia sehingga dapat mendukung kemajuan bangsa dan negara. Salah satu wujud pendidikan yang penting bagi manusia adalah keterampilan, karena dengan adanya keterampilan bisa membuat seseorang memiliki kreativitas dan mengembangkan aktivitasnya. Di zaman modern ini keterampilan yang banyak dibutuhkan salah satunya yaitu keterampilan berbahasa. Seseorang dapat berkomunikasi menggunakan bahasa karena ia mempunyai keterampilan berbahasa yang bisa diperoleh melalui pembelajaran Bahasa Indonesia. Pembelajaran Bahasa Indonesia, terutama di jenjang sekolah dasar terdiri dari empat keterampilan berbahasa yaitu, keterampilan menyimak atau mendengarkan (listening skills), keterampilan berbicara (speaking skills), keterampilan membaca (reading skills), dan keterampilan menulis (writing skills) yang keempatnya tersebut saling berkaitan satu dengan yang lainnya (Tarigan, 2015: 1).

Pemerolehan data dari wawancara dan observasi yang dilakukan pada hari Sabtu, 23 November 2019 di SDN Tambakrejo menunjukkan bahwa: (1) guru belum menggunakan model pembelajaran yang inovatif dan variatif; (2) guru belum melakukan pembelajaran yang menarik; (3) kurangnya motivasi dari guru; dan (4) banyak siswa yang masih mengalami kesulitan pada mata pelajaran Bahasa Indonesia. Kondisi tersebut menyebabkan Penilaian Tengah Semester 1 (PTS 1) siswa pada pembelajaran Bahasa Indonesia terdapat nilai yang kurang dari KKM (Kriteria Ketuntasan Minimal) yaitu 75. Dari jumlah 28 siswa di kelas $\mathrm{V}$ terdapat 9 siswa (32\%) memperoleh nilai di atas KKM dan 19 siswa (68\%) memperoleh nilai di bawah KKM, dengan nilai rata-rata kelas sebesar 67,86.

Dari uraian permasalahan tersebut, maka diperlukan adanya peningkatan pada hasil belajar Bahasa Indonesia dengan perbaikan kualitas pembelajaran melalui model pembelajaran yang tepat. Model pembelajaran yang dapat diterapkan untuk meningkatkan hasil belajar Bahasa Indonesia yaitu model Cooperative Integrated Reading and Composition (CIRC). Model pembelajaran ini cocok diterapkan bagi siswa kelas V SD yang memiliki karakteristik suka berkelompok. Shoimin (2016: 51) berpendapat bahwa model Cooperative Integrated Reading and Composition (CIRC) merupakan model pembelajaran khusus mata pelajaran bahasa dalam rangka membaca dan menemukan ide pokok, pokok pikiran, atau tema sebuah wacana. Model pembelajaran ini menekankan kepada siswa agar aktif dalam membaca dan menemukan informasi pada sebuah bacaan. Sedangkan menurut Ngalimun (2015: 240) model pembelajaran Cooperative Integrated Reading and Composition (CIRC) merupakan komposisi terpadu antara membaca dan menulis secara kooperatifkelompok. Model ini merupakan model pembelajaran bahasa khususnya membaca dan menulis yang dilakukan secara berkelompok. Kemudian berdasarkan penelitian yang dilakukan oleh Durukun (2010) dapat disimpulkan bahwa model CIRC lebih efektif untuk meningkatkan keterampilan membaca dan menulis dibandingkan metode tradisional. Dalam pembelajaran Bahasa Indonesia keterampilan membaca, dan keterampilan menulis sangat diperlukan sehingga dapat meningkatkan hasil belajar siswa.

Berdasarkan uraian di atas, peneliti melakukan penelitian dengan tujuan: (1) mendeskripsikan langkah-langkah penerapan model CIRC; (2) meningkatkan hasil belajar Bahasa Indonesia melalui penerapan model CIRC; (3) dan mendeskripsikan kendala dan solusi penerapan model $C I R C$ dalam peningkatan hasil belajar Bahasa Indonesia.

\section{METODE PENELITIAN}

Penelitian Tindakan Kelas (PTK) kolaboratif ini dilaksanakan di SDN Tambakrejo Kecamatan Buluspesantren, Kabupaten Kebumen. Waktu pelaksanaan pada semester II tahun ajaran 2019/2020. Subjek penelitian ini sebanyak 28 siswa 
terdiri dari 16 siswa perempuan dan 12 siswa laki-laki. Teknik pengumpulan data terdiri dari nontes dan tes. Teknik uji validitas data menggunakan triangulasi sumber yang berasal dari guru dan siswa serta triangulasi teknik yang digunakan yaitu wawancara, observasi dan tes evaluasi hasil belajar siswa. Teknik analisis data menggunakan 3 langkah yaitu: reduksi data, penyajian data, dan penarikan kesimpulan. Target indikator kinerja yaitu pelaksanaan penggunaan model Cooperative Integrated Reading and Composition (CIRC) untuk meningkatkan hasil belajar Bahasa Indonesia mencapai $85 \%$. Penelitian tindakan kelas ini dilaksanakan dalam dua siklus. Setiap siklus memuat empat tahap kegiatan yaitu perencanaan, pelaksanaan tindakan, pengamatan, dan refleksi.

\section{HASIL DAN PEMBAHASAN}

Penggunaan model Cooperative Integrated Reading and Composition (CIRC) untuk meningkatkan hasil balajar Bahasa Indonesia pada siswa kelas V SDN Tambakrejo dilakukan dalam dua siklus. Masing-masing siklus terdiri dari dua pertemuan dengan alokasi waktu 140 menit setiap pertemuan.

Penggunaan model CIRC menurut Amri (2013: 17) terdapat enam langkah yaitu: (1) membentuk kelompok yang anggotanya 4 orang secara heterogen; (2) guru memberikan wacana/kliping sesuai dengan topik pembelajaran; (3) siswa bekerja sama saling membacakan dan menemukan ide pokok dan memberi tanggapan terhadap wacana/kliping dan ditulis pada lembar kertas; (4) mempresentasikan/membacakan hasil kelompok; (5) Guru membuat kesimpulan bersama; (6) penutup. Shoimin (2016: 53) membagi langkah-langkah model pembelajaran CIRC menjadi lima fase, yaitu: (1) orientasi, (2) organisasi, (3) pengenalan konsep, (4) publikasi, dan (5) penguatan dan refleksi. Berdasarkan kedua pendapat tersebut dapat disimpulkan bahwa langkah model CIRC yaitu: (1) orientasi, (2) pembentukan kelompok secara heterogen, (3) pembagian bacaan sesuai dengan topik pembelajaran, (4) diskusi kelompok, (5) presentasi hasil diskusi kelompok, (6) kesimpulan, dan (7) penutup.

Perbandingan antarsiklus hasil observasi penggunaan model CIRC dapat dilihat pada tabel 1 berikut.

Tabel 1. Analisis Hasil CIRC Siklus I dan Siklus II

\begin{tabular}{lccc}
\hline & \multirow{2}{*}{ Sumber Data } & \multicolumn{2}{c}{ Siklus } \\
\cline { 3 - 4 } & & I & II \\
\hline Guru & Persentase (\%) & 82,05 & 88,57 \\
\hline Siswa & Persentase (\%) & 77,47 & 86,37 \\
\hline
\end{tabular}

Berdasarkan tabel 1 di atas, dapat diambil kesimpulan bahwa proses pembelajaran pada siklus I dan siklus II mengalami kenaikan. Hasil observasi terhadap capaian guru pada siklus I yaitu $82,05 \%$ dan pada siklus II $88,57 \%$. Hasil observasi terhadap capaian siswa pada siklus I yaitu $77,47 \%$ dan pada siklus II yaitu $86,37 \%$. Tabel 2 Analisis Perbandingan Ketuntasan Siswa Siklus I dan II

\begin{tabular}{ccccc}
\hline \multirow{2}{*}{ No. } & \multirow{2}{*}{ Siklus } & \multicolumn{3}{c}{ Tuntas (\%) } \\
\cline { 3 - 5 } & & Pertemuan 1 & Pertemuan 2 & Rata-rata \\
\hline 1 & I & 60.71 & 71.43 & 66.07 \\
2 & II & 85.71 & & 85.71 \\
\hline
\end{tabular}

Berdasarkan tabel 2 dapat diketahui bahwa rata-rata ketuntasan hasil belajar siswa dalam pembelajaran dengan model CIRC pada siklus I dan II selalu meningkat. Rata-rata ketuntasan pada siklus II sebesar $85,71 \%$ sudah mencapai target indikator kinerja penelitian yaitu $85 \%$. berikut.

Uraian mengenai langkah-langkah model CIRC dalam pembelajaran sebagai

a. Orientasi 
Pada langkah orientasi guru melakukan apersepsi dan menyampaikan tujuan pembelajaran. Dalam kegiatan apersepsi guru menanyakan materi pembelajaran yang lalu dan mengaitkan dengan materi yang akan dipelajari. Hal ini sesuai dengan pendapat dari Mushawwir dan Umar (2014: 127) yang menyatakan bahwa apersepsi adalah menghubungkan pelajaran lama dengan pelajaran baru sebagai batu loncatan sejauh mana anak didik menguasai pelajaran lama sehingga dengan mudah menyerap pelajaran baru.

b. Pembentukan Kelompok Secara Heterogen

Langkah ini dilakukan guru dengan membagi kelompok yang terdiri dari 4 siswa pada setiap kelompok dan terdiri dari siswa laki-laki dan perempuan dengan tingkat kemampuan yang berbeda. Kegiatan pembelajaran dengan cara berkelompok sesuai dengan pendapat Erikson (Sobur, 2016: 121) bahwa karakteristik siswa kelas $\mathrm{V}$ yaitu senang berkelompok dan berorganisasi. Langkah pembentukan kelompok secara heterogen ini mengajarkan kepada siswa agar mau menerima dan bekerjasama dengan siapapun tanpa pilih kasih dan membedakan teman. Hal tersebut sesuai dengan pendapat Huda (2015: 221) yang mengungkapkan bahwa salah satu kelebihan model pembelajaran CIRC yaitu menumbuh-kembangkan interaksi sosial siswa seperti kerjasama, toleransi, komunikasi, dan menghargai gagasan orang lain.

c. Pembagian Bacaan Sesuai dengan Topik Pembelajaran

Pada langkah ini, guru membagikan bacaan sesuai dengan topik pembelajaran pada tema 7 yaitu teks narasi sejarah.

d. Diskusi Kelompok

Pada langkah ini siswa mengerjakan tugas dengan diskusi kelompok. Guru mengarahan kepada siswa bersama kelompoknya untuk menemukan informasi dengan membaca teks bacaan yang dibagikan guru. Hal ini sejalan dengan pendapat Tarigan (2015: 9) yang menyatakan bahwa tujuan utama dalam membaca adalah untuk mencari dan memperoleh informasi, mencakup isi, dan memahami makna bacaan. Setiap kelompok menyampaikan informasi yang didapat dengan tulisan pada lembar kerja siswa. Hal tersebut sesuai dengan pendapat Dalman (2016: 5) menulis didefinisikan sebagai suatu kegiatan penyampaian pesan dengan menggunakan bahasa tulis sebagai medianya.

e. Presentasi Hasil Diskusi Kelompok

Pada langkah ini setiap perwakilan kelompok maju mempresentasikan hasil diskusi kelompok. Presentasi hasil diskusi kelompok dilakukan agar siswa dapat menyampaikan informasi yang didapatkan bersama dengan kelompoknya kepada kelompok lain sehingga dapat memahami informasi yang disampaikan. Hal ini sesuai dengan pendapat Sari (2017: 282) yang menyatakan bahwa tujuan umum dari presentasi adalah untuk menyampaikan informasi kepada audiens agar menambah pemahaman audiens mengenai informasi yang disampaikan.

f. Kesimpulan

Pada langkah kesimpulan, guru dan siswa bersama-sama menyimpulkan materi yang telah dibahas. Dengan menyimpulkan materi secara bersama membuat siswa dapat berpikir dan berani mengungkapkan kesimpulan materi yang telah dibahas. Hal ini sesuai dengan pendapat Shadiq (Sumartini, 2015: 3) yang mengemukakan bahwa penalaran adalah suatu proses berpikir untuk membuat suatu kesimpulan.

g. Penutup

Pada langkah penutup, siswa yang mendapat nilai hasil evaluasi terbaik diberi reward oleh guru. Dengan pemberian reward menjadikan siswa lebih semangat dalam belajar dan bersaing sehat untuk meraih prestasi. Hal tersebut sejalan dengan pendapat Marta (2016: 2430) yang menyatakan bahwa pemberian 
reward terbukti memberikan motivasi kepada siswa untuk melakukan sesuatu seperti berlomba agar dapat ditunjuk oleh guru dan menjawab pertanyaan.

Peningkatan hasil belajar Bahasa Indonesia siswa berhasil jika persentase hasil belajar Bahasa Indonesia siswa mencapai indikator kinerja penelitian sebesar $85 \%$. Hasil observasi pada siklus I rata-rata persentase hasil belajar Bahasa Indonesia siswa hanya mencapai $66,07 \%$. Hal ini disebabkan siswa masih kesulitan dalam memahami materi pembelajaran. Namun pada siklus II persentase rata-rata hasil belajar siswa meningkat menjadi $85,71 \%$. Hal ini sejalan dengan pendapat Hadiwinarto dan Novianti (2015: 2) yang menyatakan bahwa tujuan pokok dari penerapan model pembelajaran $C I R C$ yaitu mendorong siswa melakukan kelompok kerjasama yang dibentuk khusus untuk meningkatkan keterampilan memahami teks, membaca, dan menulis. Dalam pembelajaran Bahasa Indonesia keterampilan memahami teks, membaca, dan menulis sangat diperlukan sehingga dapat meningkatkan hasil belajar siswa. Berdasarkan pembahasan tersebut dapat disimpulkan bahwa penggunaan model $C I R C$ dapat meningkatkan hasil belajar Bahasa Indonesia siswa pada tema Peristiwa dalam Kehidupan di kelas V SDN Tambakrejo tahun ajaran 2019/2020.

Berdasarkan hasil observasi langkah model $C I R C$ ditemukan beberapa kendala yaitu: (1) siswa kurang aktif menjawab pertanyaan guru; (2) terdapat siswa yang masih sulit memahami materi; (3) banyak siswa yang tidak berani maju menyampaikan hasil diskusi; dan (4) siswa kesulitan menyampaikan pendapat. Adapun solusi yang dapat diterapkan guru yaitu : (1) memberikan penghargaan bagi siswa yang aktif menjawab pertanyaan; (2) memberikan bimbingan bagi siswa yang kesulitan memahami materi; (3) menunjuk siswa maju mempresentasikan hasil diskusi; dan (4) memberikan bimbingan dan penghargaan kepada siswa yang berani menyampaikan pendapat.

\section{SIMPULAN DAN SARAN}

Berdasarkan hasil penelitian dan pembahasan yang telah diuraikan, maka simpulan dari penelitian ini adalah: (1) Penggunaan model Cooperative Integrated Reading and Composition (CIRC) untuk meningkatkan hasil belajar Bahasa Indonesia pada tema Peristiwa dalam Kehidupan di kelas V SD Negeri Tambakrejo tahun ajaran 2019/2020 dilaksanakan dengan langkah-langkah: (a) orientasi, (b) pembentukan kelompok secara heterogen, (c) pembagian bacaan sesuai dengan topik pembelajaran, (d) diskusi kelompok, (e) presentasi hasil diskusi kelompok, (f) kesimpulan, dan (g) penutup. Hasil capaian guru meningkat dari $82,05 \%$ pada siklus I dan siklus II meningkat menjadi $88,57 \%$. Hasil capaian siswa meningkat dari $77,47 \%$ pada siklus I dan siklus II meningkat menjadi 86,37\%. (2) Penggunaan model CIRC dapat meningkatkan hasil belajar Bahasa Indonesia pada tema Peristiwa dalam Kehidupan di kelas V SD Negeri Tambakrejo tahun ajaran 2019/2020 yang dibuktikan dengan ratarata ketuntasan hasil belajar siswa pada siklus I mencapai $66,07 \%$ dan meningkat menjadi $85,71 \%$ pada siklus II. (3) Kendala yang muncul pada penggunaan model Cooperative Integrated Reading and Composition (CIRC) untuk meningkatkan hasil belajar Bahasa Indonesia pada tema Peristiwa dalam Kehidupan di kelas V SD Negeri Tambakrejo tahun ajaran 2019/2020 yaitu (a) siswa kurang aktif menjawab pertanyaan guru; (b) terdapat siswa yang masih sulit untuk memahami materi; (c) banyak siswa yang tidak berani maju untuk menyampaikan hasil diskusi; dan (d) siswa masih kesulitan saat menyampaikan pendapat. Solusi yang diterapkan yaitu (a) memberikan penghargaan bagi siswa yang aktif menjawab pertanyaan; (b) memberikan bimbingan bagi siswa yang mengalami kesulitan memahami materi; (c) menunjuk siswa maju mempresentasikan hasil diskusi; dan (d) memberikan bimbingan dan penghargaan kepada siswa yang menyampaikan pendapat.

Berdasarkan simpulan yang telah dipaparkan, peneliti memberikan beberapa saran: (1) bagi guru, model CIRC hendaknya menjadi rekomendasi untuk menerapkannya pada mata pelajaran Bahasa Indonesia di tema yang lain sesuai 
dengan langkah penerapannya, sehingga dapat menjadikan siswa aktif, percaya diri, dan memiliki pengetahuan yang lebih bermakna; (2) bagi siswa, siswa lebih aktif dan percaya diri dalam mengikuti pembelajaran sehingga lebih mudah dalam memahami materi dan dapat meningkatkan hasil belajar; (3) bagi sekolah, sebaiknya sekolah menyediakan referensi sumber belajar yang lebih beragam agar guru dapat berinovasi menggunakan berbagai sumber belajar sehingga pembelajaran dapat berjalan aktif, kreatif, inovatif, dan memberikan pengalaman yang bermakna kepada siswa; (4) bagi penelitian selanjutnya, peneliti selanjutnya dapat menggunakan model ini untuk melakukan penelitian pada mata pelajaran Bahasa Indonesia di tema lain misalnya pada pembelajaran yang membahas mengenai pokok pikiran, teks deskripsi, teks eksplanasi, dan lainnya.

\section{DAFTAR PUSTAKA}

Amri, S. (2013). Pengembangan \& Model Pembelajaran dalam Kurikulum 2013. Jakarta: Prestasi Pustaka Plubisher.

Dalman. (2016). Keterampilan Menulis. Jakarta: PT Raja Grafindo Persada.

Durukun, E. (2010). Effect of Cooperative Integrated Reading and Composition (CIRC) technique on reading-writing skills. Academic journals, 6 (1), 102-109.

Hadiwinarto \& Novianti. (2015). The Effects of Using CIRC Model on the English Learning Skills among Junior High School Student. Journal of Education and Learning. Vol.9 (2), 117-124.

Huda, M. (2015). Model-model Pengajaran dan Pembelajaran: Isu-isu Metodis Paradigmatis. Yogyakarta: Pustaka Pelajar.

Marta, E.D. (2016). Implementasi Pemberian Reward kepada Siswa SD Muhammadiyah Bantul Kota. Jurnal Pendidikan Guru Sekolah Dasar, 5 (25), 2430.

Mushawwir, M.A., \& Umar, F. (2014). Studi tentang Keterampilan Guru dalam Melaksanakan Apersepsi pada Pembelajaran PPKN di SMP Negeri 1 dan SMP Negeri 2 Benteng Kabupaten Kepulauan Selayar. Jurnal Tomalebbi, 1 (2), 127.

Ngalimun. (2015). Strategi dan Model Pembelajaran. Yogyakarta: Aswaja Pressindo.

Sari, D.P. (2017). Penerapan Metode Presentasi Ilmiah Berbasis Poster untuk Meningkatkan Keterampilan Berbicara Siswa Kelas V Sekolah Dasar. Jurnal Khazanah Sekolah Dasar, 5 (1), 282.

Shoimin, A. (2016). 68 Model Pembelajaran Inovatif dalam Kurikulum 2013. Yogyakarta: Ar-Ruzz Media.

Sobur, A. (2016). Psikologi Umum. Bandung: CV Pustaka Setia.

Sumartini, T.S. (2015). Peningkatan Kemampuan Penalaran Matematis Siswa Melalui Pembelajaran Berbasis Masalah. Jurnal Pendidikan Matematika, 5 (1), 3.

Tarigan, H.G. (2015). Membaca Sebagai Suatu Keterampilan Berbahasa. Bandung: Angkasa Bandung. 